\title{
Work pressure and job dissatisfaction: Challenges in Danish general practice
}

\author{
ANNE SOPHIE OXHOLM ${ }^{1}{ }^{*}$ \\ THOMAS ALLEN ${ }^{1,2}$ \\ DORTE GYRD-HANSEN ${ }^{1}$ \\ DORTE EJG JARBØL ${ }^{3}$ \\ RIKKE VOGNBJERG SYDENHAM ${ }^{3}$ \\ LINE BJØRNSKOV PEDERSEN ${ }^{1,3}$
}

\footnotetext{
${ }^{1}$ Danish Centre for Health Economics, Department of Public Health, University of Southern Denmark, Denmark

${ }^{2}$ Manchester Centre for Health Economics, University of Manchester, England

${ }^{3}$ Research Unit for General Practice, University of Southern Denmark, Denmark
}

\begin{abstract}
A main objective of the Nordic healthcare systems is to deliver timely and equal access to high-quality healthcare to the entire population. Health care providers, such as general practitioners (GPs), may therefore experience pressure to deliver care from both the health authorities and patients. However, if GPs' gains do not outweigh their costs of providing the demanded care, it may lead to job dissatisfaction and thereby potentially to poorer quality of care. This study contributes to the literature by estimating the association between different sources of experienced work pressure and job dissatisfaction among GPs. We use data from a nation-wide survey of Danish GPs distributed in 2019. The study includes six items covering GPs' experienced work pressure, which we categorise based on the degree to which they are related to demands from either patients or health authorities. Using a series of ordered logit models with a rich set of explanatory variables, we estimate the association between the pressure measures and GP job dissatisfaction. We find that GPs reporting high or considerable work pressure have an increased likelihood of also reporting job dissatisfaction. However, we find considerable heterogeneity in this relationship across different sources of work pressure as well as across GP, practice, and area characteristics. For example, the relationship between pressure from patients' demands for consultations and job dissatisfaction is stronger among GPs practicing in areas with an undersupply of GPs. Solo practitioners, who cannot share their administrative burdens with colleagues, experience a stronger association between pressure from the health authorities and job dissatisfaction. Policymakers should consider this heterogeneity when implementing new schemes and organisational structures affecting GPs' work pressure.
\end{abstract}

JEL classification: I10, I11

Keywords: general practice, job satisfaction, pressure, workload, Denmark

"Correspondence to: Anne Sophie Oxholm, J.B. Winsløws Vej 9B, 1st floor, 5000 Odense C, Denmark. Email: asoxholm@sdu.dk.

Published: Online January 2022. dx.doi.org/10.5617/njhe.8319 


\section{Introduction}

The objective of the Nordic healthcare systems is to deliver timely and equal access to highquality health care for the entire population. Primary care and in particular general practitioners (GPs) constitute a cornerstone in these healthcare systems (Olsen et al., 2016). A key task for policymakers is therefore to ensure that GPs deliver care in alignment with these objectives. This task requires an in-depth understanding of GPs' behaviour.

Health economists often assume that GPs provide care to maximise their own utility (Scott, 2000), which may be proxied by their job satisfaction (Shields et al., 2001; LévyGarboua et al., 2004). To predict GPs' behaviour, we therefore need to identify factors related to their job dissatisfaction. One of these factors may be the demands GPs face from their patients and the third-party payer (Blomqvist, 1991), which is typically the health authorities in a Nordic setting. These demands may be experienced as pressure related to the provision of different tasks, e.g. provision of consultations, services within consultations, implementation of clinical guidelines, paperwork etc. Our study aims to estimate how GPs' experienced pressure from demands are associated with GPs' job dissatisfaction.

Following the literature on GPs' decision-making (e.g. Ellis et al. (1986); Jacobson et al. (2017)), the relationship between GP $i$ 's utility, $u_{i}$, and their provision of care, $q_{i}$, may be expressed as:

$$
u_{i}\left(q_{i}\right)=\alpha_{i} b_{i}\left(q_{i}\right)+\rho_{i} r_{i}\left(q_{i}\right)-\gamma_{i} c_{i}\left(q_{i}\right)
$$

Where $b_{i}\left(q_{i}\right)$ is their patients' benefits, $r_{i}\left(q_{i}\right)$ is their revenue, and $c_{i}\left(q_{i}\right)$ is their direct and indirect costs from providing care. A standard result in the literature is that GPs provide care until their marginal gains are equal to their marginal costs of care (Ellis et al., 1986). Their marginal gains arise from patients' benefits from the additional care, but also from monetary benefits if their remuneration is linked to care provision. Their marginal costs may be both direct in the form of use of additional resources, i.e. personnel and equipment, and indirect in the form of loss of own leisure time due to longer workdays.

GPs may face demands from both the health authorities and patients to deliver care (Blomqvist, 1991). These demands can lead GPs to experience pressure, which may change their utility from providing care. The relationship between GPs' experienced pressure and utility from providing care may either be positive or negative or absent. A negative relationship may, for example, occur if GPs' experience pressure as a psychological disutility, making leisure time more valuable to them, and thereby increasing their costs of care, $\gamma_{i} c_{i}\left(q_{i}\right)$. Another example could be if pressure is related to higher costs from interactions with the patients and/or the health authorities about their (different) demands. This could be the case if the patient demands a different treatment than recommended by the health authorities, and the GP feels pressured to convince the patient of the recommended treatment. There may also exist a positive relationship between experienced pressure and utility from providing care. For example, GPs experiencing pressure from demands may perceive their care as more meaningful and important, increasing their utility from patients' benefits, $\alpha_{i} b_{i}\left(q_{i}\right)$, and monetary benefits, $\rho_{i} r_{i}\left(q_{i}\right)$. Overall, some GPs may experience the costs they derive from pressure to outweigh the benefits, leading to a utility loss (increased job dissatisfaction). Other GPs may experience the benefits they derive from pressure to outweigh the costs, such that they do not experience a utility loss, but potentially a utility gain (decreased job dissatisfaction). The relationship between experienced pressure and job dissatisfaction may therefore vary across different types of GPs and across different sources of pressure. 
From the policymakers' perspective, demanding care from GPs may align with reaching the objectives of the healthcare system. However, if GPs feel that the derived benefits do not outweigh the costs of pressure from the demanded care, they may become dissatisfied, which potentially leads to reduced quality of care and/or reduced access to services. Empirical studies confirm that GPs' job dissatisfaction is related to lower quality of care (Williams et al., 2003; Scheepers et al., 2015; Nørøxe et al., 2019). GPs who are dissatisfied with their work may also choose to leave the profession earlier. In countries like Denmark and the UK, GPs are reporting high intentions to quit, and this decision has been shown to be associated with job dissatisfaction (Scott et al., 2006; Brett et al., 2009; Hann et al., 2011; Doran et al., 2016; Andersen et al., 2018; Gibson et al., 2018).

Our study builds on the many studies focusing on GPs' job satisfaction (e.g. in an English setting: Whalley et al. (2008); Allen et al. (2017); in a Danish setting: Pedersen et al. (2020)) as well as on studies focusing on GPs' work pressure (for example in a U.S. setting: Neprash et al. (2019); Freedman et al. (2021), in a Greek setting: Tsiga et al. (2013)). The literature is, however, scarce on how GPs' work pressure relates to their job dissatisfaction. Instead, there exists several studies on GP stress and burnout (Shanafelt et al., 2015; Nørøxe et al., 2019), which are potential psychological consequences of work pressure that may link to job satisfaction. As our study does not investigate such mechanisms, we do not focus on this literature, but instead on the literature investigating the direct association between work pressure and job dissatisfaction.

A systematic literature review by Van Ham et al. (2006) includes studies from the U.S., the U.K, Israel, Estonia, New Zealand, Australia, Spain, Lithuania, Ireland and Norway on the association between work pressure and job dissatisfaction. Van Ham et al. (2006) conclude that low income, too many working hours, administrative burdens, heavy workload, lack of time, and lack of recognition may contribute to job dissatisfaction among GPs. Van Ham et al. (2006) thereby suggest that work pressure is associated with GPs' job dissatisfaction, but do not point to the source of the pressure. Mello et al. (2004) focus on specialist physicians in the U.S. and find widespread dissatisfaction among physicians practicing in high-liability environments. They point towards financial and administrative burdens being important drivers of job dissatisfaction. Lopes et al. (2014) study European workers in a broad sense. They find that increased work pressure is associated with increasing job dissatisfaction. Our study contributes to this literature by investigating how experienced pressure from different types of demands from the patients and the health authorities are related to job dissatisfaction among GPs. As GPs' preferences for delivering care may differ (and thereby their response to pressure), we also explore the heterogeneity in this relationship across different subgroups of GPs. The purpose of our investigation is to improve the understanding of factors related to GPs' job dissatisfaction and thereby potentially to their provision of care.

Our study is based on the Danish general practice setting. Studies show that Danish GPs' job dissatisfaction has increased over the last decade (Pedersen et al., 2012; Pedersen et al., 2020). Simultaneously, they face an expected increasing work pressure from both their patients and the health authorities (for further details see Section 2). The Danish general practice setting is therefore relevant for studying the association between experienced work pressure and job dissatisfaction. Although, our results are based on the Danish setting, the issue of increased pressure on GPs is relevant in other contexts. Studies also report increasing demands from both patients and the health authorities (e.g. through clinical guidelines, an ageing population etc.) in the other Nordic countries (Fredriksson et al., 2014; Olsen et al., 2016). 


\section{Institutional setting}

Similar to other countries, Denmark is experiencing a decline in the GP workforce. As of January 2020, there were 3,326 GPs in Denmark working across 1,666 practices. The number of GPs has decreased by $8 \%$ since 2010 , and more than two-thirds of all practices were closed for uptake ${ }^{1}$ in 2020 (The Organisation of General Practitioners in Denmark, 2020b), indicating that many GPs are working up to their capacity constraints.

Danish GPs work as private contractors for the public health authorities, who remunerate them through a mix of capitation and fee-for-service (Olsen et al., 2016). In recent years, GPs face increased political expectations to deliver primary prevention and to treat early discharged patients from hospitals, while delivering high-quality care (Olsen et al., 2016). In addition, GPs recently (2016-2018) completed an accreditation process aimed at promoting quality of care and patient safety (Pedersen et al., 2020). Further, in 2019 initiatives were taken to engage GPs in quality improvement through participation in peer clusters (The Danish Regions, 2017). Danish GPs have also been increasingly exposed to new guidelines and recommendations issued by the Danish Health Authority and the Danish College of General Practitioners. GPs are expected to follow these guidelines in consideration of the individual patient (The Danish College of General Practitioners, 2019).

In parallel to the many quality initiatives, The Danish Patient Safety Authority performs planned and reactive risk-based inspections in general practice. These inspections can be initiated due to patient complaints or enquiries to the authorities (The Danish Patient Safety Authorities, 2020b). The Danish Patient Safety Authority can temporarily suspend a GP's authority to practice, and may take the GP to court (The Danish Patient Safety Authorities, 2020a). Danish GPs are therefore facing both demands and regulations from health authorities as well as quality controls. These factors may cause GPs to experience increasing work pressure from the health authorities.

The number of Danish citizens has increased by $5 \%$ from 5.5 million to 5.8 million since 2008. At the same time, both the share of elderly citizens and the number of patients with one or more chronic conditions have increased substantially (Willadsen et al., 2016; The Organisation of General Practitioners in Denmark, 2020b). The challenges with an ageing patient population with more chronic conditions combined with decreasing lengths of stay at hospitals result in increasing demands also from the patients (Olsen et al., 2016).

\section{Data}

This study uses data from the first wave (2019) of our GP work-life panel targeting all Danish GPs. We designed the survey specifically to measure GPs' job dissatisfaction and experiences of work pressure. The following subsections describe the included variables.

\subsection{Job dissatisfaction and work pressure variables}

We include a measure of overall job dissatisfaction using a four-point Likert scale going from very satisfied to very dissatisfied. This job dissatisfaction question has previously been used in several GP work-life surveys in Denmark, making comparisons across surveys and years possible (Pedersen et al. (2012), Riisgaard et al. (2017), and Pedersen et al. (2020)).

Our measures of pressure are inspired by the English GP work-life longitudinal panel surveys that include questions on GPs' experienced pressure in their working lives (Gibson et al., 2018). Our study includes six measures of work pressure that GPs may experience from the patients and the health authorities. Figure 1 illustrates each pressure measure on a spectrum from patient pressure to health authority pressure.

\footnotetext{
${ }^{1}$ When Danish GPs have 1,600 patients on their list, they can close for further patient uptake.
} 
We interpret the questions about both patients' demands for consultations and demands from patients (within consultations) as patient-driven factors. The latter question refers to patients' demands for specific services within the consultation, whereas the former question refers to their demands for getting consultations. We capture health authoritydriven pressures by asking the respondents about the demands from health authorities and control. The first pressure measure relates to requirements through regulations, e.g. new guidelines, while the later refers to health authorities' surveillance of GPs, e.g. through audits and inspections.

Other pressure-inducing factors may be driven by both patients and the health authorities. Among such factors are the risks of complaints, which can cause pressure both due to fear of patient dissatisfaction and reputational concern and due to risks of inspections from authorities. Pressure from paperwork can be induced by patients, e.g. if they request a medical certificate to their employer or insurance company, while health authorities can induce pressure, e.g. through a request for a medical certificate or documentation used for quality assurance. However, the content of paperwork was open for interpretation by the respondents.

Figure 1: Measures of GP work pressure related to patients and health authorities.

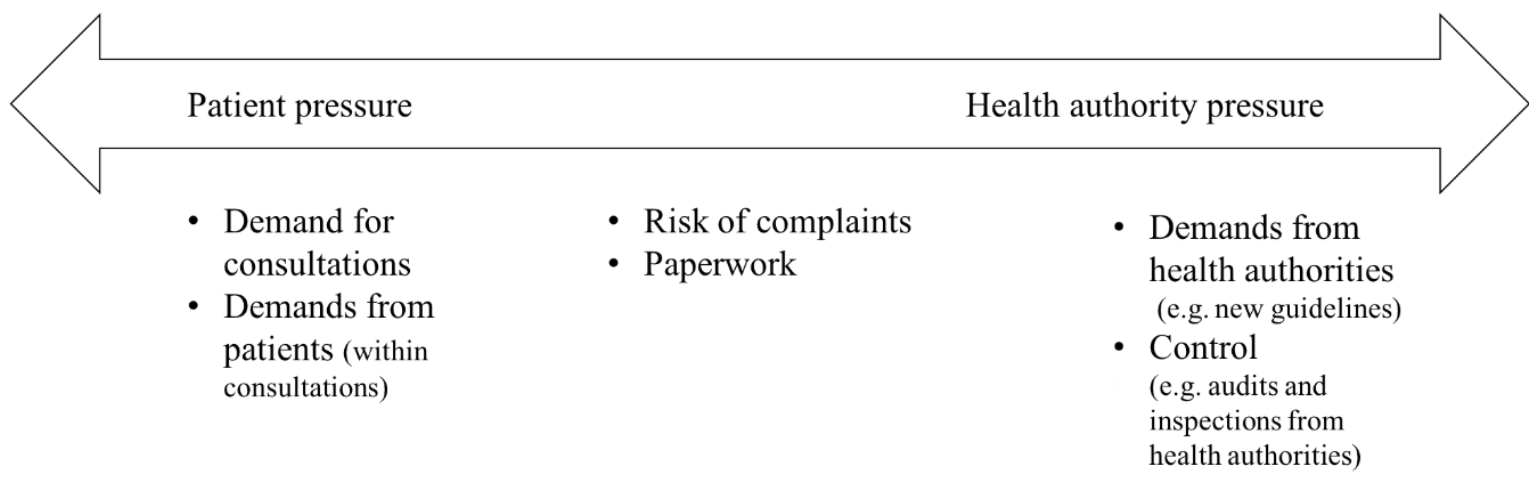

Common for all measures of pressure we include is that GPs may or may not perceive them as inducing pressure in their working lives. We measure each variable on a five-point Likert scale ranging from high pressure to no pressure to capture the subjective experience of pressure. This scale was also used in the English GP work-life longitudinal panel surveys (Gibson et al., 2018).

\subsection{GP, practice, and area characteristics}

We include information on GPs' age and gender as well as their practice type (solo or partnership) from the Health Professionals Register and the Danish eHealth Portal. We also make use of several measures of the characteristics of the area the GPs were operating in. Using data from the survey and Danmarks Adressers Web API (DAWA), we measure which one of the five Danish regions as well as the 98 municipalities the practices were located in. We measure the degree of urbanisation of the practice's municipality using Statistics Denmark's definition, which is based on the population density as well as the number of inhabitants in the largest city (Statistics Denmark, 2020). We also include an indicator of whether GPs were located in a postal code area defined as being in threat of not having primary care coverage, i.e. these areas had a severe undersupply of GPs. This indicator was created by the Danish Regions to determine the size of the differentiated capitation payments to the practices in 2018 to 2020 (The Organisation of General Practitioners in Denmark, 
2020a). Practices located in other areas may, however, also have experienced a lack of GPs. Appendix 1 provides a detailed description of all included variables.

\subsection{Data linkage}

We include information on each practice's provider number as well as its address from The Danish Health Authorities' Organisation Register. The Danish Regions uses this register for reimbursement of the GPs, and it is therefore of high validity. This information is linked to information on the number of GPs in each practice and the names of the GPs from a publicly available website (Danish eHealth Portal). This website is administered by the Danish Regions and is of high validity. Next, we include data from The Health Professionals Register on GPs' authorisation ID and birth date. As The Danish Patient Safety Authority uses this register to keep track of the authorisation to practice for all health professionals in Denmark, we consider it valid. We use the authorisation ID as a unique identifier of a GP in the survey data. Lastly, information on the practice postal code is linked to information on whether GPs were operating in an area with an undersupply of general practices (from the publicly available websites dawa.aws.dk and laeger.dk/laegedaekningstruede-omraader) and to information on the municipality's degree of urbanisation (from Statistics Denmark).

\subsection{Pilot testing of survey}

Before distributing the full survey, we pilot tested the questionnaires in nine think-aloud interviews with GPs and subsequently further tested it in a quantitative pilot test of a random sample of 100 GPs. As the feedback on the questions in the pilot study was positive, we used the same questions in our full survey.

\subsection{Survey data collection}

Invitation letters were sent by regular mail to all 3,336 GPs registered with a practice provider number at the Danish Health Authorities' Organisation Register. The letters contained a link to an online survey and a personal code that should be used to access the questionnaire. To reduce the risk of a biased sample, we only informed the GPs about the general theme of the survey, and they were not provided with any further details relating to the research objective of the survey. We advertised the questionnaire to the GPs in their regional newsletters and sent them two reminders. The survey opened June 2019 and terminated in September 2019. In total, 1,239 GPs responded to the survey. Our analysis sample consists of the 1,217 GPs who answered all relevant questions.

\section{Method}

This study aims to analyse how different experienced work pressures are related to GPs' job dissatisfaction. As job dissatisfaction is measured on a four-point Likert-scale $(j=1, \ldots, 4)$, which increases in dissatisfaction, we estimate an ordered logit regression of GP $i$ 's job dissatisfaction $d_{i}$ as:

$$
\operatorname{Prop}\left(d_{i}=j\right)=F\left(\boldsymbol{p}_{i}^{\prime} \gamma+\boldsymbol{x}_{i}^{\prime} \beta\right)=\frac{\exp \left[\boldsymbol{p}_{i}^{\prime} \gamma+\boldsymbol{x}_{i}^{\prime} \beta-k_{j}\right]}{1+\exp \left[\boldsymbol{p}_{i}^{\prime} \gamma+\boldsymbol{x}_{i}^{\prime} \beta-k_{j}\right]}
$$

where $\boldsymbol{p}_{\boldsymbol{i}}$ is a vector including the six measures of GP work pressure ${ }^{2}$. For each measure of pressure, we group the pressure responses measured on a five-point Likert scale

\footnotetext{
${ }^{2}$ As the measures of pressure are correlated (see Appendix 3), we investigate the degree of multicollinearity. According to Appendix 4, the highest VIF score is 2, indicating no issues with multicollinearity.
} 
in the following two groups: "no"/"slight"/"moderate" pressure and "considerable"/"high" pressure (see Appendix 2 for the number of respondents in each category). The vector $\boldsymbol{x}_{\boldsymbol{i}}$ includes characteristics of the GP, practice, and area, which may be associated with both experienced pressure and job dissatisfaction. ${ }^{3}$ The observed ordinal values of job dissatisfaction, $d_{i}$, are the result of a set of latent continuous responses, $d^{*}$, and threshold values, $k$, such that:

$$
d_{i}=\left\{\begin{array}{c}
1 \text { if } d_{i}^{*} \leq k_{1} \\
2 \text { if } k_{1}<d_{i}^{*} \leq k_{2} \\
3 \text { if } k_{2}<d_{i}^{*} \leq k_{3} \\
4 \text { if } k_{3}<d_{i}^{*}
\end{array}\right.
$$

We estimate equation (2) for our full sample of GPs as well as for subsamples of GPs. The aim of our subgroup analyses is to uncover whether GPs differ in their responses to pressure. Some GPs may perceive the benefits they derive from pressure to outweigh the costs, such that they do not experience a utility loss (job dissatisfaction). Other GPs may instead assess that the benefits do not outweigh the costs, which may lead to increased job dissatisfaction (see section 1). We take an explorative approach to this investigation by stratifying the GPs by our GP, practice, and area characteristics. ${ }^{4}$ Appendix 5 shows that there is sufficient variation in each pressure measure across the stratified samples to conduct these subgroup analyses. In the stratified sample models, the stratification variable is omitted as an explanatory variable. For all estimations, standard errors are clustered by practice to account for the dependence of observations from GPs working in the same practice.

\subsection{Supplementary analysis}

The consequences of a positive association between sources of pressure and job dissatisfaction for the healthcare system depends on the degree to which the GP population experience these pressures. As a supplementary analysis, we therefore explore the variation in experienced work pressure across our different subgroups of GPs. As we use a binary measure of pressure, we estimate a binary logit model of GP $i$ 's work pressure $p_{i}^{m}$ as:

$$
\operatorname{Prob}\left(p_{i}^{m}=1\right)=F\left(\boldsymbol{x}_{i}^{\prime} \beta^{m}\right)=\frac{\exp \left[\boldsymbol{x}_{i}^{\prime} \beta^{m}\right]}{1+\exp \left[\boldsymbol{x}_{i}^{\prime} \beta^{m}\right]}
$$

Where $p_{i}^{m}$ is a dummy equal to one if the GP experiences high or considerable work pressure of type $m$ and zero otherwise. The vector $\boldsymbol{x}_{\boldsymbol{i}}$ includes the same characteristics as in equation (2). We estimate equation (4) separately for each of the six pressure measures $(m=$ $1, \ldots, 6)$. Standard errors are clustered at the practice level.

\footnotetext{
${ }^{3}$ Our results are robust to estimating the model without including these controls, see Appendix 8 .

${ }^{4}$ Appendix 1 provides an overview of the definitions and operationalisation of these variables.
} 


\section{Results}

\subsection{Descriptive statistics}

Our survey sample of GPs is to a large extent representative of the full population of GPs in Denmark (Appendix 6). Table 1 reports descriptive statistics for our sample of 1,217 GPs. According to our survey, GPs are generally satisfied with their jobs. Around $11 \%$ of GPs report that they are dissatisfied or very dissatisfied with their jobs. This dissatisfaction, however, varies slightly across our subgroups of GPs (Appendix 7). Across pressure variables, a substantial percentage of the GPs report high or considerable work pressure. A frequently reported source of pressure is control for example in the form of audits/inspections from health authorities (48.7\%). We observe a similar large share of GPs experiencing pressure from demands from health authorities, for example in the form of guidelines (46.2\%). A large share of GPs also report high or considerable pressure from patients' demands for consultations $(46.1 \%)$.

\subsection{The association between GP work pressure and job dissatisfaction}

Table 2 reports the estimated associations between different sources of work pressure and GPs' job dissatisfaction. We find that GPs reporting higher pressure from patient demands have statistically significantly higher odds of being dissatisfied with their work. This finding applies to pressures from both demand for consultations and demands within consultations. Splitting the sample by GP, practice, and area characteristics reveal some interesting findings. The pressure from demand for consultations is most strongly associated with job dissatisfaction among GPs practicing in areas with an undersupply of GPs. The statistically significant relationship between the pressure from demand for consultations and job dissatisfaction does not exist among male GPs or solo practitioners. The pressure from demands from patients within consultations is on the other hand not statistically significantly associated with job dissatisfaction among early career GPs, GPs in small partnership practices, GPs operating in areas of high or low degree of urbanisation, and GPs practicing in areas with an undersupply of GPs.

Even though almost one-third of GPs report pressure from the risk of complaints (table 1), this pressure measure does not appear to be statistically significantly related to job dissatisfaction. Pressure from paperwork is on the other hand statistically significantly positively associated with job dissatisfaction. This relationship is strongest for solo practitioners and practices located in areas with a low degree of urbanisation. We find no statistically significant relationship between pressure from paperwork and dissatisfaction among GPs in the mid-career stage, GPs working in large partnership practices, GPs working in areas with a medium or high degree of urbanisation, or that have an undersupply of GPs.

GPs' experience of pressure from the health authorities is also statistically significantly positively related to job dissatisfaction. This relationship does not appear to be driven by control (e.g. through audits or inspections), but instead through demands from health authorities' requirements and regulations, for example in the form of guidelines. The analyses on subsample of GPs reveal some interesting findings for the relationship between demands from health care authorities and job dissatisfaction. We find the strongest association for solo practitioners, followed by GPs working in areas with a high degree of urbanisation, and GPs practicing in areas with a sufficient supply of GPs. There is no statistically significant association between demands from health authorities and job dissatisfaction for any of the other subgroups of GPs. 
Table 1: Descriptive statistics for survey sample.

\begin{tabular}{ll}
\hline & Count $(\%)$ \\
& $\mathrm{N}=1217$ \\
\hline Job dissatisfaction & \\
Very satisfied & $355(29.2 \%)$ \\
Satisfied & $734(60.3 \%)$ \\
Dissatisfied & $96(7.9 \%)$ \\
Very dissatisfied & $32(2.6 \%)$ \\
High or considerable pressure from ... & \\
Demand for consultations & $561(46.1 \%)$ \\
Demands from patients (within consultations) & $382(31.4 \%)$ \\
Risk of complaints & $358(29.4 \%)$ \\
Paperwork & $502(41.2 \%)$ \\
Control (e.g. audits/inspections from health authorities) & $593(48.7 \%)$ \\
Demands from health authorities (e.g. new guidelines) & $562(46.2 \%)$ \\
GP characteristics & \\
Male & $550(45.2 \%)$ \\
Early career & $354(29.1 \%)$ \\
Mid-career & $423(34.8 \%)$ \\
Late career & $440(36.2 \%)$ \\
Practice characteristics & \\
Solo Practice & $274(22.5 \%)$ \\
Small partnership practice & $576(47.3 \%)$ \\
Large partnership practice & $367(30.2 \%)$ \\
Area characteristics & \\
Capital Region & $311(25.6 \%)$ \\
Region Zealand & $149(12.2 \%)$ \\
Region of Southern Denmark & $306(25.1 \%)$ \\
Central Demark Region & $368(30.2 \%)$ \\
North Denmark Region & $83(6.8 \%)$ \\
High degree of urbanisation & $383(31.5 \%)$ \\
Medium degree of urbanisation & $372(30.6 \%)$ \\
Low degree of urbanisation & $462(38.0 \%)$ \\
Undersupply of GPs & $97(8.0 \%)$ \\
\hline & \\
\hline & \\
\hline
\end{tabular}

Note: The proportion responding "high or considerable pressure" are the ones who answered 4-5 on the 5point Likert scale for a given item.

\subsection{Supplementary analysis}

The consequences of the positive associations between sources of pressure and job dissatisfactions for the healthcare system depends on the degree to which the GP population experience these pressures. The share of GPs experiencing high or considerable pressure varies between $23.0 \%$ and $56.9 \%$ across subgroups and sources of pressure (Appendix 5). As a supplementary analysis, we therefore explore associations between GPs' characteristics and their experience of high or considerable work pressures.

Our supplementary analysis reveals that GP and practice characteristics are statistically significantly associated with experiencing pressure from patients (Appendix 9). Female GPs have statistically significantly higher odds of reporting high or considerable 
pressure from patients than male GPs. This finding is of interest as female GPs report a positive association between these types of pressures and job dissatisfaction (table 2). GPs in their mid-career stage also have statistically significantly higher odds of experiencing pressure from patients than GPs at their late career stage. Area characteristics does, however, not appear to be associated with experience of patient pressure. This finding is interesting as the link between patients' demand for consultations and job dissatisfaction is especially high in areas with an undersupply of GPs (table 2). Even though GPs operating in these areas do not appear to be more pressured than GPs in other areas, it is worth noting that there is a link between their pressure from demands for consultations and job dissatisfaction.

Around 29-41\% of all GPs experience pressure from paperwork and pressure due to risk of complaints (Appendix 5). There does not appear to be statistically significant differences across subgroups of GPs in their experience of these pressures (Appendix 9). Instead, we find statistically significant differences between subgroups of GPs' experience of pressures from health authorities. GPs in their mid-career stage have statistically significantly higher odds of reporting higher pressures from health authorities than early career GPs. Solo practitioners also have higher odds of reporting these types of pressures than GPs belonging to partnership practices (Appendix 9). Importantly, among the subgroups more likely to experience pressure from health authorities, it is only for solo practitioners that we find a statistically significant association between this pressure and job dissatisfaction (table 2).

\section{Discussion and concluding remarks}

Previous studies show that GPs' job dissatisfaction is related to lower quality of care and exiting the workforce (Williams et al., 2003; Scott et al., 2006; Brett et al., 2009; Hann et al., 2011; Scheepers et al., 2015; Doran et al., 2016; Andersen et al., 2018; Gibson et al., 2018; Nørøxe et al., 2019). Danish GPs have become more dissatisfied over the last decade. In 2010 only $3 \%$ of GPs were dissatisfied (Pedersen et al., 2012), whereas our study shows that this number has increased to $11 \%$ in 2019. Compared to other countries (e.g. the UK where 29\% of GPs are dissatisfied (Gibson et al. (2018)), the level of dissatisfaction among GPs in Denmark is not worrisome, but there is reason to be concerned about the time trend. Identifying factors associated with GPs' job dissatisfaction may help stall this trend.

We find that GPs' experienced work pressure is statistically significantly positively associated with their job dissatisfaction. Our finding is aligned with previous studies investigating this relationship (e.g. Mello et al. (2004); Van Ham et al. (2006)). We contribute to this literature by showing heterogeneity in this association across different sources of work pressure and subgroups of GPs. We thereby conclude that not all sources of experienced pressure are associated with job dissatisfaction for all subgroups of GPs.

We focus on different sources of experienced pressure arising from the demands of the GPs' patients and the health authorities. We find that the experienced pressure arising from patients' demand for consultations is most strongly associated with job dissatisfaction among GPs practicing in areas with a severe undersupply of GPs (see section 3.2). This finding suggests a potential negative spiral: The experienced pressure from working in an area in which patients' demands cannot be met, may cause dissatisfaction among GPs, thereby making it difficult to retain GPs. 
Table 2: Ordered logit models estimating the association between measures of pressure and job dissatisfaction.

\begin{tabular}{|c|c|c|c|c|c|c|c|c|c|c|c|c|c|c|}
\hline & $\begin{array}{l}\text { Full } \\
\text { sample }\end{array}$ & Males & Females & $\begin{array}{l}\text { Early } \\
\text { career }\end{array}$ & $\begin{array}{l}\text { Mid- } \\
\text { career }\end{array}$ & $\begin{array}{l}\text { Late } \\
\text { career }\end{array}$ & $\begin{array}{l}\text { Solo } \\
\text { practice }\end{array}$ & $\begin{array}{l}\text { Small } \\
\text { partner- } \\
\text { ship } \\
\text { practice }\end{array}$ & $\begin{array}{l}\text { Large } \\
\text { partner- } \\
\text { ship } \\
\text { practice }\end{array}$ & $\begin{array}{l}\text { High } \\
\text { degree of } \\
\text { urbani- } \\
\text { sation }\end{array}$ & $\begin{array}{l}\text { Medium } \\
\text { degree of } \\
\text { urbani- } \\
\text { sation }\end{array}$ & $\begin{array}{l}\text { Low } \\
\text { degree of } \\
\text { urbani- } \\
\text { sation }\end{array}$ & $\begin{array}{l}\text { Sufficient } \\
\text { supply of } \\
\text { GPs }\end{array}$ & $\begin{array}{l}\text { Under- } \\
\text { supply } \\
\text { of GPs }\end{array}$ \\
\hline $\begin{array}{l}\text { Demand for } \\
\text { consultations }\end{array}$ & $\begin{array}{l}2.111^{* * * *} \\
(5.03)\end{array}$ & $\begin{array}{l}1.472 \\
(1.70)\end{array}$ & $\begin{array}{l}2.915^{* * * *} \\
(5.25)\end{array}$ & $\begin{array}{l}2.363^{* *} \\
(3.00)\end{array}$ & $\begin{array}{l}2.306^{* *} \\
(3.15)\end{array}$ & $\begin{array}{l}1.872^{*} \\
(2.41)\end{array}$ & $\begin{array}{l}1.559 \\
(1.34)\end{array}$ & $\begin{array}{l}3.007^{* * * *} \\
(4.96)\end{array}$ & $\begin{array}{l}1.812^{*} \\
(2.23)\end{array}$ & $\begin{array}{l}2.340^{* *} \\
(3.06)\end{array}$ & $\begin{array}{l}1.959^{*} \\
(2.49)\end{array}$ & $\begin{array}{l}2.193^{* *} \\
(3.28)\end{array}$ & $\begin{array}{l}2.113^{* * * *} \\
(4.86)\end{array}$ & $\begin{array}{l}7.158^{* * *} \\
(2.62)\end{array}$ \\
\hline $\begin{array}{l}\text { Demands from } \\
\text { patients (within } \\
\text { consultations) }\end{array}$ & $\begin{array}{l}1.865^{* * *} \\
(3.75)\end{array}$ & $\begin{array}{l}2.352^{* * * *} \\
(3.31)\end{array}$ & $\begin{array}{l}1.558^{*} \\
(1.96)\end{array}$ & $\begin{array}{l}1.878 \\
(1.82)\end{array}$ & $\begin{array}{l}1.747^{*} \\
(2.15)\end{array}$ & $\begin{array}{l}2.399^{* * *} \\
(2.83)\end{array}$ & $\begin{array}{l}2.198^{*} \\
(2.18)\end{array}$ & $\begin{array}{l}1.469 \\
(1.58)\end{array}$ & $\begin{array}{l}2.643^{* * *} \\
(2.98)\end{array}$ & $\begin{array}{l}1.205 \\
(0.57)\end{array}$ & $\begin{array}{l}3.503^{\text {**** }} \\
(4.31)\end{array}$ & $\begin{array}{l}1.624 \\
(1.78)\end{array}$ & $\begin{array}{l}1.896^{* * *} \\
(3.74)\end{array}$ & $\begin{array}{l}0.971 \\
(-0.04)\end{array}$ \\
\hline $\begin{array}{l}\text { Risk of } \\
\text { complaints }\end{array}$ & $\begin{array}{l}1.244 \\
(1.44)\end{array}$ & $\begin{array}{l}1.227 \\
(0.88)\end{array}$ & $\begin{array}{l}1.217 \\
(0.93)\end{array}$ & $\begin{array}{l}1.139 \\
(0.42)\end{array}$ & $\begin{array}{l}1.397 \\
(1.30)\end{array}$ & $\begin{array}{l}1.147 \\
(0.52)\end{array}$ & $\begin{array}{l}1.282 \\
(0.78)\end{array}$ & $\begin{array}{l}1.109 \\
(0.47)\end{array}$ & $\begin{array}{l}1.172 \\
(0.50)\end{array}$ & $\begin{array}{l}1.444 \\
(1.35)\end{array}$ & $\begin{array}{l}1.108 \\
(0.38)\end{array}$ & $\begin{array}{l}1.165 \\
(0.59)\end{array}$ & $\begin{array}{l}1.197 \\
(1.15)\end{array}$ & $\begin{array}{l}0.789 \\
(-0.27)\end{array}$ \\
\hline Paperwork & $\begin{array}{l}1.963^{* * *} \\
(4.74)\end{array}$ & $\begin{array}{l}2.094^{* * * *} \\
(3.36)\end{array}$ & $\begin{array}{l}1.967^{* * * *} \\
(3.41)\end{array}$ & $\begin{array}{l}2.246^{* *} \\
(3.16)\end{array}$ & $\begin{array}{l}1.294 \\
(1.00)\end{array}$ & $\begin{array}{l}2.506^{* * * *} \\
(3.77)\end{array}$ & $\begin{array}{l}2.863^{* * *} \\
(3.44)\end{array}$ & $\begin{array}{l}1.800^{* *} \\
(2.82)\end{array}$ & $\begin{array}{l}1.641 \\
(1.87)\end{array}$ & $\begin{array}{l}1.422 \\
(1.44)\end{array}$ & $\begin{array}{l}1.685 \\
(1.73)\end{array}$ & $\begin{array}{l}2.730^{* * * *} \\
(4.36)\end{array}$ & $\begin{array}{l}1.914^{* * *} \\
(4.41)\end{array}$ & $\begin{array}{l}3.406 \\
(1.66)\end{array}$ \\
\hline $\begin{array}{l}\text { Control (e.g. } \\
\text { audits/inspect- } \\
\text { ions from health } \\
\text { authorities) }\end{array}$ & $\begin{array}{l}0.912 \\
(-0.57)\end{array}$ & $\begin{array}{l}1.059 \\
(0.22)\end{array}$ & $\begin{array}{l}0.798 \\
(-1.06)\end{array}$ & $\begin{array}{l}0.771 \\
(-0.82)\end{array}$ & $\begin{array}{l}1.235 \\
(0.70)\end{array}$ & $\begin{array}{l}0.879 \\
(-0.48)\end{array}$ & $\begin{array}{l}0.517 \\
(-1.94)\end{array}$ & $\begin{array}{l}1.076 \\
(0.31)\end{array}$ & $\begin{array}{l}1.270 \\
(0.74)\end{array}$ & $\begin{array}{l}1.104 \\
(0.34)\end{array}$ & $\begin{array}{l}0.786 \\
(-0.78)\end{array}$ & $\begin{array}{l}0.969 \\
(-0.11)\end{array}$ & $\begin{array}{l}0.844 \\
(-0.99)\end{array}$ & $\begin{array}{l}4.405 \\
(1.74)\end{array}$ \\
\hline $\begin{array}{l}\text { Demands from } \\
\text { health } \\
\text { authorities (e.g. } \\
\text { new guidelines) }\end{array}$ & $\begin{array}{l}1.466^{*} \\
(2.25)\end{array}$ & $\begin{array}{l}1.410 \\
(1.33)\end{array}$ & $\begin{array}{l}1.498 \\
(1.75)\end{array}$ & $\begin{array}{l}1.165 \\
(0.44)\end{array}$ & $\begin{array}{l}1.495 \\
(1.33)\end{array}$ & $\begin{array}{l}1.556 \\
(1.60)\end{array}$ & $\begin{array}{l}2.621^{* *} \\
(2.69)\end{array}$ & $\begin{array}{l}1.120 \\
(0.45)\end{array}$ & $\begin{array}{l}1.276 \\
(0.75)\end{array}$ & $\begin{array}{l}2.335^{*} \\
(2.49)\end{array}$ & $\begin{array}{l}1.055 \\
(0.17)\end{array}$ & $\begin{array}{l}1.364 \\
(1.22)\end{array}$ & $\begin{array}{l}1.508^{*} \\
(2.30)\end{array}$ & $\begin{array}{l}0.846 \\
(-0.24)\end{array}$ \\
\hline Observations & 1217 & 550 & 667 & 354 & 423 & 440 & 274 & 576 & 367 & 383 & 372 & 462 & 1120 & 97 \\
\hline
\end{tabular}

Exponentiated coefficients (odds ratios), models include explanatory variables for GP gender, age, practice type, degree of urbanisation, undersupply of GPs, and region. In the stratified sample models, the stratification variable is omitted as an explanatory variable. $z$-statistics in parentheses, standard errors clustered by practice.

${ }^{*} p<0.05,{ }^{* *} p<0.01,{ }^{* * *} p<0.001$ 
We also find a statistically significant positive association between the degree of work pressure from paperwork and job dissatisfaction. This relationship is especially strong for solo practitioners. Interestingly, solo practitioners are not experiencing more pressure from paperwork than GPs in partnership practices. A reason for our finding may be that the two groups of GPs may have different preferences. GPs working in partnership practices may be deriving greater benefits and fewer costs (psychological disutility) from the demanded activity, perhaps because it is a shared task. Irrespectively of the underlying reasons, policy initiatives reducing administrative burdens may reduce dissatisfaction especially for solo practitioners.

Our analysis shows that solo practitioners report more pressure from demands from health authorities (e.g. new guidelines) and control (e.g. audits and inspections). We observe a statistically significantly positive association between the former type of experienced pressure and dissatisfaction. Easing the process of implementing new guidelines may therefore reduce job dissatisfaction for solo practitioners. In cases where the health authorities' and patients' objectives are aligned, e.g. with respect to GPs performing annual drug controls or managing virus vaccinations to risk groups, GPs' adherence to the authorities' demands may also reduce the experienced pressure from the demands of patients (Glenngård et al., 2017). Identifying the best approach to improve GPs' adherence to these demands is beyond the scope of our study, but both financial and non-financial incentives could be used.

Interestingly, the association between experienced pressure and dissatisfaction is not present for control through audits and inspections, overall or in any of the subgroups. This finding is aligned with Pedersen et al. (2020) who do not find evidence of accreditation affecting Danish GPs' job satisfaction. We further do not find any statistically significant relationships between experienced pressure from the risk of complaints and job dissatisfaction. These results suggest that although almost half of the GPs report being pressured by control from health authorities, monitoring activities is not an issue for job satisfaction in Denmark, where health care professionals are not at high risk of facing penalties or lawsuits.

Our study design has both strengths and weaknesses. Among the strengths is the fact that we can estimate the association between job dissatisfaction and experienced work pressure for different sources of pressure as well as for different subgroups of GPs. This level of detail enables us to more precisely point to problem areas that should be of focus to policymakers. As GPs' experience of pressure for objectively defined measures may differ, it is also a strength that we use subjective measures of pressure.

The use of subjective measures does, however, create some challenges. As is a common problem when estimating the association between two subjective measures (work pressure and job dissatisfaction), we cannot rule out that unobserved personal characteristics are driving our results. For example, GPs with strong professional skills may be more likely to both thrive in their jobs and experience less pressure. Another challenge is that we cannot exclude the possibility of reversed causality. Thus, more dissatisfied workers may experience pressure more. The associations we are observing are likely to be a result of both causal directions (potentially a vicious circle). As the sample of GPs practicing in areas defined as having an undersupply of GPs is small, we should also be cautious when interpreting our estimates for this sample.

Despite the identification issues, the association between work pressure and job dissatisfaction can still guide policymakers to potential problem areas. Our study therefore serves as an important step in understanding GPs' provision of care through the relationship between experienced pressure and job dissatisfaction. Future research should focus on 
identifying a causal link between these two measures, for example by evaluating how policy schemes changing GPs' work pressure affects their job dissatisfaction.

\section{Acknowledgements}

Financial support from the Novo Nordisk Foundation (Grant number: NNF18OC0033978), Læge

Sofus Carl Emil Friis og Hustru Olga Doris Friis' Legat is gratefully acknowledged.

\section{Ethical approval}

Complying with European data protection rules, the Research \& Innovation Organisation at University of Southern Denmark registered the data processing activities for this project on behalf of the Danish Data Protection Agency (file number 10.482). The Regional Scientific Ethical Committees for Southern Denmark assessed the study and concluded that no further ethical approval was needed cf. section 14, subsection 1 in the Act on Research Ethics Review of Health Research Projects (file number 20192000-99).

\section{References}

Allen, T., Whittaker, W. and Sutton, M. (2017). Does the proportion of pay linked to performance affect the job satisfaction of general practitioners? Social Science \& Medicine, 173, 9-17.

Andersen, M. K., Pedersen, L. B. and Waldorff, F. B. (2018). Retirement, job satisfaction and attitudes towards mandatory accreditation: a Danish survey study in general practice. BMJ open, 8, e020419.

Blomqvist, ^. (1991). The doctor as double agent: Information asymmetry, health insurance, and medical care. Journal of Health Economics, 10, 411-432.

Brett, T. D., Arnold - Reed, D. E., Hince, D. A., Wood, I. K. and Moorhead, R. G. (2009). Retirement intentions of general practitioners aged 45-65 years. Medical Journal of Australia, 191, 75-77.

Doran, N., Fox, F., Rodham, K., Taylor, G. and Harris, M. (2016). Lost to the NHS: a mixed methods study of why GPs leave practice early in England. British journal of general practice, 66, e128-e135.

Ellis, R. P. and Mcguire, T. G. (1986). Provider behavior under prospective reimbursement: Cost sharing and supply. Journal of health economics, 5, 129-151.

Fredriksson, M., Blomqvist, P. and Winblad, U. (2014). Recentralizing healthcare through evidence-based guidelines-striving for national equity in Sweden. BMC health services research, 14, 1-9.

Freedman, S., Golberstein, E., Huang, T.-Y., Satin, D. J. and Smith, L. B. (2021). Docs with their eyes on the clock? the effect of time pressures on primary care productivity. Journal of Health Economics, 77, 102442.

Gibson, J., Sutton, M., Spooner, S. and Checkland, K. (2018). Ninth national GP worklife survey. Policy Research Unit in Commissioning and the Healthcare System Manchester Centre for Health Economics. University of Manchester.

Glenngård, A. H. and Anell, A. (2017). Does increased standardisation in health care mean less responsiveness towards individual patients' expectations? A register-based study in Swedish primary care. Sage open medicine, 5, 2050312117704862.

Hann, M., Reeves, D. and Sibbald, B. (2011). Relationships between job satisfaction, intentions to leave family practice and actually leaving among family physicians in England. The European Journal of Public Health, 21, 499-503. 
Jacobson, M. G., Chang, T. Y., Earle, C. C. and Newhouse, J. P. (2017). Physician agency and patient survival. Journal of economic behavior \& organization, 134, $27-47$.

Lévy-Garboua, L. and Montmarquette, C. (2004). Reported job satisfaction: what does it mean? The Journal of Socio-Economics, 33, 135-151.

Lopes, H., Lagoa, S. and Calapez, T. (2014). Work autonomy, work pressure, and job satisfaction: An analysis of European Union countries. The Economic and Labour Relations Review, 25, 306-326.

Mello, M. M., Studdert, D. M., Desroches, C. M., Peugh, J., Zapert, K., Brennan, T. A. and Sage, W. M. (2004). Caring for patients in a malpractice crisis: physician satisfaction and quality of care. Health Affairs, 23, 42-53.

Neprash, H. T. and Barnett, M. L. (2019). Association of primary care clinic appointment time with opioid prescribing. JAMA network open, 2, e1910373-e1910373.

Nørøxe, K. B., Pedersen, A. F., Carlsen, A. H., Bro, F. and Vedsted, P. (2019). Mental wellbeing, job satisfaction and self-rated workability in general practitioners and hospitalisations for ambulatory care sensitive conditions among listed patients: a cohort study combining survey data on GPs and register data on patients. BMJ quality \& safety, 28, 997-1006.

Olsen, K. R., Anell, A., Häkkinen, U., Iversen, T., Ólafsdóttir, T. and Sutton, M. (2016). General practice in the Nordic countries. Nordic Journal of Health Economics, 4, 56-67.

Pedersen, L. B., Allen, T., Waldorff, F. B. and Andersen, M. K. K. (2020). Does accreditation affect the job satisfaction of general practitioners? A combined panel data survey and cluster randomised field experiment. Health Policy, 124, 849-855.

Pedersen, L. B., Kjær, T., Kragstrup, J. and Gyrd-Hansen, D. (2012). General practitioners' preferences for the organisation of primary care: a discrete choice experiment. Health Policy, 106, 246-256.

Riisgaard, H., Søndergaard, J., Munch, M., Le, J. V., Ledderer, L., Pedersen, L. B. and Nexøe, J. (2017). Associations between degrees of task delegation and job satisfaction of general practitioners and their staff: a cross-sectional study. BMC health services research, 17, 44.

Scheepers, R. A., Boerebach, B. C., Arah, O. A., Heineman, M. J. and Lombarts, K. M. (2015). A systematic review of the impact of physicians' occupational well-being on the quality of patient care. International journal of behavioral medicine, 22, 683698.

Scott, A. (2000). Economics of general practice. Handbook of health economics, 1, 11751200.

Scott, A., Gravelle, H., Simoens, S., Bojke, C. and Sibbald, B. (2006). Job satisfaction and quitting intentions: a structural model of British general practitioners. British Journal of Industrial Relations, 44, 519-540.

Shanafelt, T. D., Hasan, O., Dyrbye, L. N., Sinsky, C., Satele, D., Sloan, J. and West, C. P. (2015). Changes in burnout and satisfaction with work-life balance in physicians and the general US working population between 2011 and 2014. Mayo clinic proceedings, 90 (12) ,1600-1613.

Shields, M. A. and Ward, M. (2001). Improving nurse retention in the National Health Service in England: the impact of job satisfaction on intentions to quit. Journal of health economics, 20, 677-701.

Statistics Denmark (2020). Degree of Urbanisation (DEGURBA) [Online]. Available: https://www.dst.dk/da/Statistik/dokumentation/nomenklaturer/urbaniseringsgrad-degurba----danmarks-statistik [Accessed July 16 2020]. 
The Danish College of General Practitioners (2019). Kliniske vejledninger og FAQta-ark [Online].

Available:

https://www.dsam.dk/dsam_mener/holdninger_og_politikker/kliniske-

vejledninger-og-faqta-

ark/\%20and\%20here:\%20https://vejledninger.dsam.dk/statuskons/

[Accessed

October 19 2020].

The Danish Patient Safety Authorities (2020a). Fratagelse af autorisation eller frivillig fraskrivelse [Online]. Available: https://stps.dk/da/tilsyn/tilsyn-medsundhedspersoner/fratagelse-af-autorisation-eller-frivillig-fraskrivelse/ [Accessed June 30 2020].

The Danish Patient Safety Authorities (2020b). Om tilsyn [Online]. Available: https://stps.dk/da/tilsyn/om-tilsyn/ [Accessed June 30 2020].

The Danish Regions (2017). Overenskomst for almen praksis.

The Organisation of General Practitioners in Denmark (2020a). Laegedakningstruede områder [Online]. Available: https://www.laeger.dk/laegedaekningstruedeomraader\#Kort1 [Accessed July 16 2020].

The Organisation of General Practitioners in Denmark (2020b). PLO faktaark 2020. 1-36.

Tsiga, E., Panagopoulou, E., Sevdalis, N., Montgomery, A. and Benos, A. (2013). The influence of time pressure on adherence to guidelines in primary care: an experimental study. BMJ open, 3 (4), e002700.

Van Ham, I., Verhoeven, A. A., Groenier, K. H., Groothoff, J. W. and De Haan, J. (2006). Job satisfaction among general practitioners: a systematic literature review. The European journal of general practice, 12, 174-180.

Whalley, D., Gravelle, H. and Sibbald, B. (2008). Effect of the new contract on GPs' working lives and perceptions of quality of care: a longitudinal survey. British Journal of General Practice, 58, 8-14.

Willadsen, T. G., Bebe, A., Køster-Rasmussen, R., Jarbøl, D. E., Guassora, A. D., Waldorff, F. B., Reventlow, S. and Olivarius, N. D. F. (2016). The role of diseases, risk factors and symptoms in the definition of multimorbidity-a systematic review. Scandinavian journal of primary health care, 34, 112-121.

Williams, E. S. and Skinner, A. C. (2003). Outcomes of physician job satisfaction: a narrative review, implications, and directions for future research. Health care management review, 28, 119-139.

(C) 2022 by the author(s). This article is an open access article distributed under the terms and conditions of the Creative Commons Attribution license (http://creativecommons.org/licenses/by/4.0/). 